\title{
Mapeamento de competências em bibliotecas e unidades de informação
}

Iara Rodrigues de Amorim

\author{
Bibliotecária - Biblioteca Central do Campus de \\ Ribeirão Preto da Universidade de São Paulo \\ (BCRP/USP). Especialização em Gestão de \\ Unidades de Informação
}

Roniberto Morato do Amaral

\section{Professor Adjunto da UFSCar, Departamento Ciência da Informação Resumo}

O presente artigo apresenta uma sistemática para mapear os atributos de competência (conhecimentos, habilidades e atitudes), necessários à atuação do profissional bibliotecário. A pesquisa-ação e a aplicação foram realizadas junto à Biblioteca Central do Campus de Ribeirão Preto da Universidade de São Paulo (BCRP/USP). Foram identificados os atributos, assim como a importância e o domínio de cada um deles, pela equipe BCRP/USP. Conclui-se que a sistemática fornece referências importantes para a gestão de pessoas em bibliotecas e unidades de informação.

Palavras-chave: Mapeamento de competências; Profissional da informação; Bibliotecários; Gestão de pessoas por competências; Administração de unidades de informação.

\section{Mapping of competences in libraries and information units}

This paper presents a scheme to map the attributes of competence (knowledge, skills and attitudes) required for the librarian's work. The research and its application were done at the Central Library of the University of São Paulo, Campus of Ribeirão Preto (BCRP/USP). The attributes were identified, as well as the importance and domain of each of them for BCRP/USP librarians. It was concluded that the scheme is suitable for providing some important 
references for people management in libraries and information units.

Keywords: Mapping of Competences; Information Professional Management; Librarians Management; People Management Based on Competences; Information Units Management.

Recebido em 15.09.2009 Aceito 01.06.2011

\section{Introdução}

A nova configuração do mundo globalizado e as mudanças de mentalidade verificadas nos últimos vinte anos afetaram as relações no ambiente de trabalho, o modo de encarar o papel do trabalhador, a responsabilidade da empresa perante as pessoas que nela trabalham, mas, também, encontram ali, um lugar para desenvolver suas potencialidades como seres humanos (DUTRA, 2001). É, nesse contexto, que o modelo tradicional (estratégia de controle) de organizar o trabalho e gerenciar pessoas diverge da realidade das organizações. É necessário substituir, como unidade básica de gestão, o cargo pela pessoa, visando identificar as competências necessárias e as que se têm por desenvolver, para uma atuação eficaz e eficiente e aliá-las aos objetivos estratégicos da organização, um desafio para a sobrevivência de ambos os lados, dos trabalhadores e da organização. Com isso, o conceito de competência e o modelo de Gestão de Pessoas por Competências (GPPC) ganham impulso tanto no mundo acadêmico como no empresarial (ZARIFIAN, 2001).

Dentro deste complexo cenário, as bibliotecas e unidades de informação, como organismos sociais vivos que são, necessitam evoluir e acompanhar as transformações de sua sociedade. Com o intuito de contribuir para o aumento da eficiência e eficácia das bibliotecas e unidades de informação no âmbito da gestão de pessoas, o presente trabalho teve como objetivo geral mapear os atributos de competência (conhecimentos, habilidades e atitudes) necessários a atuação do profissional bibliotecário, com vistas ao estabelecimento do processo de Gestão de Pessoas Por Competências (GPPC) em bibliotecas e unidades de informação.

Entendem-se como atributos de competência: o "saber", que a pessoa acumulou ao longo da vida (conhecimentos - corresponde a uma série de informações assimiladas e estruturadas pelo indivíduo, que the permitem "entender o mundo" (DURAND, 2000), o "saber fazer" (habilidades - capacidade de fazer uso produtivo do conhecimento, ou seja, de instaurar conhecimentos e utilizá-los em uma ação (DURAND, 2000) e o "saber ser" (atitudes - refere-se aos aspectos sociais e afetivos relacionados ao trabalho (DURAND, 2000; FLEURY; FLEURY, 2001). Dessa forma, ser competente passa a ser a consequência da utilização adequada, pelo bibliotecário, de seus atributos de competência, isto é, dos 
conhecimentos, habilidades e atitudes que possui e que são compatíveis com a função biblioteconômica que ele desempenha.

\section{Discutindo competência, GPPC e o profissional da informação}

As organizações buscam indivíduos, não somente pelo seu conhecimento técnico, mas privilegiam pessoas com habilidades e atitudes compatíveis com as suas estratégias, objetivos e valores. Buscam-se profissionais responsáveis por seu autodesenvolvimento, por sua capacidade de lidar com os imprevistos e de superar as expectativas, com vontade e capacidade de criar, inovar e, obviamente, de se comprometer com a organização do qual fará parte. Profissionais com este perfil, ou seja, multifuncionais, com visão global, vontade de aprender e de sentirse corresponsável pela melhoria da organização da qual faz parte, sobressaem-se no mercado de trabalho, pois têm vontade de ir além, ao que diz respeito ao desempenho de suas atividades, desenvolvendo, assim, suas competências individuais (ARTHUR; ROUSSEAU, 1996).

Nas bibliotecas e unidades de informação, a realidade não é diferente: o profissional é reconhecido pelo seu conhecimento técnico, indiscutível e necessário a qualquer profissão, mas isso não é o suficiente para atender e, sobretudo, superar as necessidades e expectativas dos usuários. É fundamental aos bibliotecários, e por que não estender a todos os demais profissionais, a reflexão sobre sua atuação profissional, ao mesmo tempo em que cabe às organizações a responsabilidade por incentivar e providenciar condições aos seus trabalhadores para 0 aprendizado contínuo e liberdade para inovar.

O que entra em questão, portanto, seria qual o melhor método de gerenciar pessoas, já que constituem o principal recurso para as organizações alcançarem vantagem competitiva e sucesso no mundo globalizado. Um modelo de gestão de pessoas é a forma de organizar e gerir o comportamento humano dentro das organizações, o modelo compreende princípios, políticas e processos que interferem nas relações humanas no interior da organização, além do estilo de gestão dos gestores diretos das equipes de trabalho (FISCHER, 2002). Sabe-se, pois, que a forma tradicional de administrar pessoas, a estrutura funcional, caracterizada pelo comando e controle, não atende mais às necessidades e expectativas dos trabalhadores e das organizações, assim, neste contexto, o conceito de competências apresenta-se fortemente vinculado ao desenvolvimento e ao aprendizado, tanto no âmbito individual como organizacional (ZARIFIAN, 2001).

Segundo Dutra (2001), competência deve ser compreendida como o conjunto de conhecimentos, habilidades e atitudes necessários para que o profissional desenvolva suas atribuições e responsabilidades. Fleury e Fleury (2001, p. 188), por sua vez, definem competência como "um saber agir responsável e reconhecido, que implica mobilizar, integrar, transferir 
conhecimentos, recursos e habilidades, que agreguem valor econômico à organização e valor social ao indivíduo". As definições deixam claras as três dimensões da competência: o "saber" (conhecimentos), o "saber fazer" (habilidades) e o "saber ser" (atitudes). Dessa forma, ser bibliotecário competente passa a ser a consequência da utilização adequada pelo profissional de seus atributos de competência, isto é, dos conhecimentos, habilidades e atitudes que possui e que são compatíveis com a função biblioteconômica que ele desempenha.

Neves (2002) destacou as habilidades próprias do profissional da informação bibliotecário: avaliar os efeitos do uso da informação na organização; classificar, representar e armazenar informações; conhecer o material apropriado para a organização e para o cliente; desenvolver e localizar produtos de informação especializados; dominar sistemas de indexação; estruturar, catalogar e analisar criticamente informações; julgar informações necessárias; possuir conhecimento de softwares de armazenagem de informações; reconhecer a informação útil para a criatividade dos indivíduos; e ter competência na organização, tratamento e disseminação da informação.

De acordo com Valentim (2000), na proposta de diretrizes curriculares, elaboradas pelo Ministério da Educação (MEC), para a área de Ciência da Informação, mencionam-se as atitudes e procedimentos essenciais aos profissionais da área: capacidade de trabalhar em equipes profissionais; criatividade; curiosidade intelectual e postura investigativa para continuar aprendendo; espírito associativo; flexibilidade e capacidade de adaptação; respeito à ética e aos aspectos legais da profissão; rigor e precisão; sensibilidade para a necessidade informacional de usuários reais e potenciais; e senso crítico.

No Brasil, o Ministério do Trabalho e Emprego (MTE) disponibiliza a Classificação Brasileira de Ocupações (CBO/2002) (BRASIL, 2007). Entende-se por ocupação, a agregação de empregos ou situações de trabalho similares quanto às atividades realizadas. Na CBO/2002 (BRASIL, 2007), os Profissionais da Informação tratam do desenvolvimento, gestão e organização dos recursos informacionais; nesta categoria se enquadram os profissionais bibliotecário, documentalista e analista de informações (pesquisador de informações em rede) (BRASIL, 2007). Já na literatura da área de Ciência da Informação é possível encontrar outros profissionais que possuem a informação como cerne da sua atuação, como por exemplo, o profissional gestor do conhecimento (NEVES, 2002); o profissional de inteligência competitiva (AMARAL et al., 2008) e o profissional da informação - categoria onde se encaixam os bibliotecários (VALENTIM, 2000). As semelhanças entre suas competências foram encontradas na pesquisa de Neves (2002), que comparou habilidades e competências entre $o$ gestor do conhecimento e o profissional da informação. É possível afirmar que, mesmo variando as funções destes profissionais, as atividades não fogem do ciclo de vida da informação: produção, identificação, coleta (busca), análise, processamento, disseminação e avaliação - presente no cotidiano destes profissionais. De 
acordo com Neves (2002), dentre outras semelhanças encontradas, destacam-se:

a) analisar qual informação será relevante e como aproveitá-la da melhor maneira, seja voltada para recuperação das informações, tomada de decisões ou para a geração do conhecimento;

b) os profissionais têm que conhecer bem o conteúdo dos recursos informacionais e fazerem uso eficiente das tecnologias de informação; e

c) foco comum: atender as necessidades e expectativas informacionais dos clientes internos e externos das organizações nas quais prestam serviço.

O uso do conceito de competência permitiu o surgimento de uma gestão de pessoas mais alinhada com as expectativas e com as necessidades das organizações e dos indivíduos (ARTHUR; ROUSSEAU, 1996; DUTRA, 2004). A GPPC visa reconhecer, formar e ampliar conhecimentos, habilidades e atitudes, de forma a agregar valor à organização e ao indivíduo, através de subsistemas: treinamento e desenvolvimento, recrutamento e seleção, avaliação de desempenho, carreira e sucessão, segurança e saúde ocupacional, relações trabalhistas e remuneração (DUTRA, 2001). Esse modelo é particularmente útil às organizações, para as quais o aprimoramento, a inovação e a aprendizagem organizacional são determinantes para a sua sobrevivência. Nesse sentido, há grande potencial da aplicação do modelo de GPPC às bibliotecas e unidades de informação, pois estas necessitam de um ambiente propício para desenvolver a criatividade $e$, consequentemente, inovar seus produtos e serviços informacionais (VALENTIM, 2008).

Um dos primeiros passos para a implantação da GPPC em uma organização é a realização do mapeamento das competências, que servirá de base para o modelo de GPPC. Faz parte do processo de mapeamento a elucidação das competências dos cargos da organização, através do levantamento dos atributos de competência (conhecimento, habilidade e atitude), os quais são reunidos por semelhança e convertidos em competências (RUZZARIN et al., 2002). Segundo McLagan (1997), existem várias abordagens para o mapeamento de competências, dentre as quais se destacam as aplicações de entrevistas aos atuais trabalhadores, identificando situações e desafios que eles já enfrentaram, observação (análise do trabalho, de seus resultados e do que é necessário para alcançá-los), além de simulações realizando suposições sobre o ambiente e o futuro do trabalho.

\section{Aplicação do mapeamento de competências do profissional da informação bibliotecário}


Motivada pela necessidade de alinhar demandas, serviços, produtos, recursos e pessoal disponível, de modo a alcançar um planejamento coerente com a realidade (desafios atuais) e antecipar-se aos desafios futuros, a Biblioteca Central do Campus da USP de Ribeirão Preto (BCRP/USP), objeto de estudo deste trabalho, aplicou no primeiro semestre de 2009 uma sistemática para mapear as competências da sua equipe de bibliotecários, com o intuito de operacionalizar a GPPC na organização.

Devido às semelhanças entre as competências dos profissionais envolvidos com o ciclo de vida da informação identificadas na literatura da área da Ciência da Informação, aplicou-se a sistemática de mapeamento de competências desenvolvida por meio de pesquisa-ação (COUGHLAN; COUGHLAN, 2002) e apresentada no QUADRO 1. A sistemática é composta por uma sequência de atividades, uso de ferramentas para suporte às atividades e resultados bem definidos.

A BCRP/USP é uma biblioteca universitária subordinada ao Sistema Integrado de Bibliotecas da Universidade de São Paulo (SIBi/USP), composto por um conjunto de 43 Bibliotecas, instaladas junto às Unidades Universitárias dos diversos "campi". A BCRP/USP é formada pela integração dos acervos bibliográficos de 07 faculdades sediadas no Campus de Ribeirão Preto: Escola de Enfermagem; Faculdade de Ciências Farmacêuticas; Faculdade de Filosofia, Ciências e Letras; Faculdade de Economia, Administração e Contabilidade; Faculdade de Medicina; Faculdade de Odontologia; Escola de Educação Física e Esporte e o Curso de Música de Ribeirão Preto da ECA-USP (MORAES, 2008).

QUADRO 1 - Modelo para o mapeamento de competências em IC

\begin{tabular}{|c|c|c|c|}
\hline Atividade & Descrição & Ferramentas & Resultados \\
\hline 1 & Caracterizar a unidade de informação & $\begin{array}{l}\text { Técnica de } \\
\text { análise SWOT }\end{array}$ & $\begin{array}{l}\text { Missão } \\
\text { Objetivos } \\
\text { Visão }\end{array}$ \\
\hline 2 & Mapeamento de processos & $\begin{array}{l}\text { Observação } \\
\text { Sistema de } \\
\text { Gestão da } \\
\text { Qualidade }\end{array}$ & Processos \\
\hline 3 & $\begin{array}{l}\text { Coleta das percepções sobre a competência } \\
\text { da equipe }\end{array}$ & \multirow[t]{2}{*}{$\begin{array}{l}\text { Formulário de } \\
\text { coleta de } \\
\text { percepções de } \\
\text { competências }\end{array}$} & $\begin{array}{c}\text { Percepções de } \\
\text { competência } \\
\text { da equipe }\end{array}$ \\
\hline 4 & $\begin{array}{l}\text { Conversão das percepções em } \\
\text { características positivas }\end{array}$ & & $\begin{array}{l}\text { Características } \\
\text { positivas }\end{array}$ \\
\hline 5 & $\begin{array}{l}\text { Classificação das características positivas em } \\
\text { atributos de competência }\end{array}$ & $\begin{array}{c}\text { Glossário de } \\
\text { atributos de } \\
\text { competências }\end{array}$ & $\begin{array}{c}\text { Atributos de } \\
\text { competência } \\
(\mathrm{CHA})\end{array}$ \\
\hline 6 & $\begin{array}{l}\text { Elaboração dos indicadores de competência } \\
\text { da equipe: } \\
\text { - Indicador de importância dos atributos de } \\
\text { competência; } \\
\text { - Indicador do nível de domínio dos atributos } \\
\text { de competência pela equipe }\end{array}$ & $\begin{array}{l}\text { Planilha } \\
\text { eletrônica }\end{array}$ & $\begin{array}{c}\text { Indicadores de } \\
\text { competências } \\
\text { da equipe }\end{array}$ \\
\hline
\end{tabular}

Fonte: Adaptado de RUZZARIN et al. (2002); MCLAGAN (1997) e AMARAL et al. (2008). 
O processo de mapeamento de competências na BCRP/USP, compreendeu todas as atividades mencionadas no QUADRO 1 , e sua realização ocorreu no período de março a maio de 2009:

Atividade 1: Caracterização da unidade de informação BCRP/USP: baseou-se na compreensão e avaliação da missão, objetivos, visão e do planejamento estratégico, através da aplicação da técnica SWOT - A técnica de análise de informações SWOT visou diagnosticar os ambientes interno e externo à organização (pontos fortes, pontos fracos, oportunidades e ameaças) (TARAPANOFF, 2001). Além de ser essencial para o direcionamento do desenvolvimento das competências dos profissionais nas organizações, facilitou neste trabalho a identificação das competências organizacionais necessárias para que a organização atinja seus objetivos estratégicos e também colaborou na comprovação dos resultados obtidos com o mapeamento de competências.

Atividade 2: Mapeamento dos processos da BCRP/USP: esta atividade permitiu que fossem conhecidas com detalhe e profundidade todas as operações que ocorrem na BCRP/USP e todos os recursos necessários (financeiro, pessoal, informacional, tempo) durante a produção de um serviço e/ou produto. Os processos foram mapeados através das técnicas do Sistema de Gestão da Qualidade, implementado no início do segundo semestre de 2004 (MORAES, 2008).

Atividade 3: Coleta das percepções sobre a competência da equipe de bibliotecários da BCRP/USP: a organização possui 13 bibliotecários; para a coleta das percepções respeitou-se as categorias de bibliotecário existentes na BCRP/USP, doravante denominadas grupos:

GRUPO 1: Bibliotecário de aquisição e tombamento;

GRUPO 2: Bibliotecário de processamento técnico;

GRUPO 3: Bibliotecário de referência; e

GRUPO 4: Bibliotecário gestor.

Atribuiu-se aos bibliotecários da BCRP/USP a responsabilidade por indicar suas percepções quanto à atuação dos quatros grupos de bibliotecários (Aquisição e tombamento, Processamento técnico, Referência e Gestor). A coleta foi realizada por meio de um instrumento de pesquisa testado e validado em trabalhos anteriores, quando foi utilizado para a coleta de percepções sobre competências em inteligência competitiva (AMARAL et al., 2008; AMARAL; GARCIA; ALLIPRANDINI, 2008). Para a aplicação na área de Biblioteconomia, tal instrumento de pesquisa passou pela avaliação de dois especialistas para verificação da adequação de conteúdo da linguagem, com base no contexto da atuação 
profissional em Biblioteconomia. O instrumento de pesquisa compreendeu as seguintes questões abertas:

a) Quais características positivas para o desenvolvimento das suas atividades na BCRP/USP o "GRUPO N" possui? (GOSTO). Essa questão buscou coletar conhecimentos, habilidades e atitudes que os membros da equipe apreciam em seus colegas durante a realização das atividades biblioteconômicas;

b) Quais características negativas para o desenvolvimento das suas atividades na BCRP/USP o "GRUPO N" possui? (NÃO GOSTO). Essa questão buscou coletar conhecimentos, habilidades e atitudes que os membros da equipe não apreciam em seus colegas, durante a realização das atividades biblioteconômicas; e

c) Quais características positivas para o desenvolvimento das suas atividades na BCRP/USP o "GRUPO N" deveria possuir? (IDEAL SERIA). Essa questão explicitou os conhecimentos, habilidades e atitudes ainda não estabelecidos, porém julgados necessários pela equipe para que o desenvolvimento das suas atividades na BCRP/USP torne-se mais eficiente e eficaz.

Atividade 4: Conversão das percepções em características positivas. Conforme visualizado nos exemplos presentes no QUADRO 2.

QUADRO 2 - Conversão das percepções em características positivas.

\begin{tabular}{|c|c|c|}
\hline \multicolumn{2}{|c|}{ Percepção dos membros } & \multirow{2}{*}{$\begin{array}{l}\text { Características } \\
\text { positivas }\end{array}$} \\
\hline $\begin{array}{c}\mathbf{G} \\
\mathbf{0} \\
\mathbf{s} \\
\mathbf{t} \\
\mathbf{0}\end{array}$ & $\begin{array}{l}\text { Procede } \\
\text { criteriosamente sobre a } \\
\text { seleção e aquisição de } \\
\text { material bibliográfico }\end{array}$ & \\
\hline $\begin{array}{c}\mathbf{N} \\
\tilde{\mathbf{a}} \\
\mathbf{0} \\
\mathbf{G} \\
\mathbf{0} \\
\mathbf{s} \\
\mathbf{t} \\
\mathbf{0}\end{array}$ & $\begin{array}{l}\text { Falta de domínio de } \\
\text { informática }\end{array}$ & $\begin{array}{l}\text { Conhecer tecnologia da } \\
\text { informação }\end{array}$ \\
\hline $\begin{array}{c}\mathbf{I} \\
\mathbf{d} \\
\mathbf{e} \\
\mathbf{a} \\
\mathbf{I} \\
\mathbf{S} \\
\mathbf{e} \\
\mathbf{r i} \\
\mathbf{a}\end{array}$ & $\begin{array}{l}\text { Toma iniciativa no } \\
\text { trabalho }\end{array}$ & Ter iniciativa \\
\hline
\end{tabular}

Atividade 5: Classificação das características positivas em atributos de competência. Os próprios respondentes (bibliotecários), baseados no 
glossário de competências (AMARAL et al., 2008), classificaram as características positivas em atributos de competência. O glossário de competências é composto por 46 Habilidades, 25 Atitudes e 19 Conhecimentos, ordenados alfabeticamente, sendo que cada atributo acompanha sua respectiva descrição de significado, a fim de manter a concordância no processo de comunicação durante a coleta dos dados.

Portanto, a função do glossário é permitir a obtenção de um consenso sobre os atributos de competência, de forma que os membros da equipe possuam a mesma compreensão de seus significados. A classificação é um processo iterativo, com refinamento gradual, na medida em que os respondentes se familiarizavam com os conceitos. Nos casos em que não foi possível converter uma característica positiva em atributo, permitiu-se a inserção de um novo atributo pelo respondente. O QUADRO 3 apresenta a classificação das características positivas em atributos de competência.

QUADRO 3 - Classificação das características positivas em atributos de competência

\begin{tabular}{|c|c|}
\hline Características positivas & Conhecimento \\
\hline $\begin{array}{l}\text { - Dominar os recursos da informática } \\
\text { - Gostar de informática } \\
\text { - Conhecer recursos de tecnologia da } \\
\text { informação. }\end{array}$ & $\begin{array}{l}\text { Tecnologia da } \\
\text { informação: } \\
\text { Conhecimento em } \\
\text { hardware } \\
\text { (equipamentos) e } \\
\text { softwares (aplicativos) } \\
\text { relacionados à sua } \\
\text { função. }\end{array}$ \\
\hline Características positivas & Habilidade \\
\hline $\begin{array}{l}\text { - Organização no trabalho } \\
\text { - Ser organizado } \\
\text { - } \quad \text { Priorizar tarefas. }\end{array}$ & $\begin{array}{l}\text { Organização e } \\
\text { planejamento: } \\
\text { Capacidade de } \\
\text { organizar e estabelecer } \\
\text { ordem de prioridade às } \\
\text { tarefas, mesmo diante } \\
\text { de situações diversas, e } \\
\text { otimizar procedimentos } \\
\text { em favor da eficácia em } \\
\text { resultados. }\end{array}$ \\
\hline Características positivas & Atitude \\
\hline $\begin{array}{l}\text { - Colaborar com a equipe de trabalho } \\
\text { - Auxiliar na resolução de problemas } \\
\text { - Dar sugestões de melhorias mesmo fora } \\
\text { do setor ao qual pertence/trabalha. }\end{array}$ & $\begin{array}{l}\text { Cooperação: Interesse } \\
\text { e disponibilidade para } \\
\text { ajudar outras pessoas } \\
\text { na realização dos } \\
\text { trabalhos e consecução } \\
\text { de objetivos, } \\
\text { compartilhando } \\
\text { conhecimentos, } \\
\text { informações, } \\
\text { incentivando a troca e o } \\
\text { interesse pelo }\end{array}$ \\
\hline
\end{tabular}


Atividade 6: Elaboração dos indicadores de competência da equipe. $\mathrm{Na}$ última atividade do mapeamento, a partir da análise dos atributos coletados pela aplicação, foram elaborados dois indicadores de competência da equipe de bibliotecários da BCRP/USP: a) importância dos atributos de competência e b) nível de domínio dos atributos de competência pela equipe. Esses indicadores, apresentados na FIG. 2, permitem uma visualização quase imediata dos pontos fortes e fracos da equipe de bibliotecários da BCRP/USP.

\section{Resultados e discussões}

O mapeamento de competências dos bibliotecários da BCRP/USP resultou em um total de 761 percepções (ou indicadores) de competência, o que representa uma média de indicações por respondente de 58,5 percepções.

A cobertura do glossário de competências mostrou-se plenamente eficiente, uma vez que apenas 05 percepções de competência $(0,66 \%)$ indicadas não foram classificadas diretamente pelos respondentes. Das 05 percepções indicadas, havia 01 atributo de competência correspondente no glossário, 02 foram consideradas não aplicáveis e 02 foram consideradas novos atributos a serem inseridos no glossário: "Foco no cliente" e "Trabalhar em equipe", sendo que ambos os novos atributos foram classificados como habilidades. Tal procedimento foi realizado pelo responsável pelo mapeamento. Portanto, foram mapeados na equipe de bibliotecários da BCRP/USP 375 indicadores de competência para o atributo "Habilidade", 246 para o atributo "Atitude" e 138 para o atributo "Conhecimento", conforme é apresentado na FIG. 1.



Atributos de competência

$\square$ GOSTO $\square$ NAO GOSTO $\square$ IDEAL SERIA 
FIGURA 1 - CHA versus Status dos bibliotecários da BCRP/USP

Fonte: Dados da pesquisa.

Considerando os atributos com maior número de indicações (percepções) a ele associadas (i.e., considerando a soma das respostas "GOSTO" + "NÃO GOSTO" + "IDEAL SERIA"), temos que:

a) Se o "GOSTO" supera em muito a soma ("NÃO GOSTO" + "IDEAL SERIA"), a equipe reconhece e valoriza esse atributo (provável PONTO FORTE da equipe), um valor positivo para o Indicador nível de domínio dos atributos de competência pela equipe, o que nos leva a crer que não constitui um fator crítico melhorá-lo; e

b) Se a soma ("NÃO GOSTO" + "IDEAL SERIA") supera em muito o "GOSTO", a equipe crê que precisa desse atributo, e que ele precisa ser melhorado (é um provável PONTO FRACO da equipe), representa um valor negativo para o Indicador nível de domínio dos atributos de competência pela equipe.

Com essas informações, é possível mensurar a importância do atributo e o seu domínio pela equipe BCRP/USP. O Indicador de importância dos atributos de competência pode ser visualizado (FIG. 2) na distribuição geral dos atributos na equipe. Alguns atributos ocorrem com maior intensidade que outros. Como se trata de uma soma de percepções ("GOSTO" + "NÃO GOSTO" + "IDEAL SERIA"), os atributos de maior ocorrência representam a visão da equipe sobre o que é mais importante. Sendo assim, os atributos "Tecnologia da informação, "Cooperação", "Organização e planejamento", "Pró-atividade", "Língua estrangeira", "Motivação" e "Apresentação de resultados" de maior soma, seriam os principais candidatos à gestão por competências da equipe BCRP/USP. É possível esperar que as competências organizacionais relacionem-se aos atributos de maior ocorrência do "GOSTO", relacionados à existência do atributo na equipe, entre eles estão: "Organização e planejamento", "Destreza com as fontes" e "Fontes de informação", o que corrobora com a literatura (NEVES, 2002) que versa sobre as competências do profissional da informação bibliotecário.

A partir da análise do Indicador nível de domínio dos atributos de competência pela equipe BCRP/USP, foi possível visualizar vários atributos reconhecidos pela equipe como pontos a serem melhorados, como por exemplo, os atributos "Tecnologia da informação", "Proatividade" e "Língua estrangeira", que apresentam uma significativa diferença entre o "GOSTO" e a soma ("NÃO GOSTO" + "IDEAL SERIA"), isto é, um baixo nível de domínio do atributo de competência pela equipe. Já os atributos "Organização e planejamento" e "Destreza com as fontes" podem ser reconhecidos claramente como pontos fortes da equipe.

A significativa indicação para o atributo "Tecnologia da informação" possivelmente deve-se às mudanças que as tecnologias da informação e comunicação estão provocando nas bibliotecas, principalmente nas 
bibliotecas universitárias - por exemplo, ambientes virtuais interativos e colaborativos, multiplicidade de repositórios institucionais digitais com informações científicas e tecnológicas, entre outras. Este atributo recebeu $100 \%$ de indicações para os tipos de respostas "NÂO GOSTO" + "IDEAL SERIA", caracterizando-se como algo crítico para a organização.

Também são atributos a serem melhorados aqueles considerados estratégicos pela organização e que possuem baixa incidência. A percepção dada pelo modelo da existência de pontos fortes e fracos na equipe permite o estabelecimento de referência para o julgamento por parte da organização e identificar se o nível de competências existente satisfaz às demandas oriundas tanto da estratégia organizacional como dos projetos a serem assumidos pela equipe. Essa percepção é vital no sentido de conscientizar a equipe para ações de reorganização, capazes de viabilizar a realização das funções biblioteconômicas e de manter as competências da equipe continuamente alinhadas à estratégia da BCRP/USP.

Os resultados do mapeamento apresentam os primeiros insights para a GPPC na organização, viabilizando a construção de soluções que aumentem a eficiência da equipe frente aos desafios atuais, tanto pela superação dos pontos fracos como pela valorização dos pontos fortes, além de permitir a busca de novas possibilidades de atuação pela valorização dos pontos fortes já existentes. Esses são processos

gerenciados, cabíveis no contexto da GPPC por se basearem nos atributos de competência.

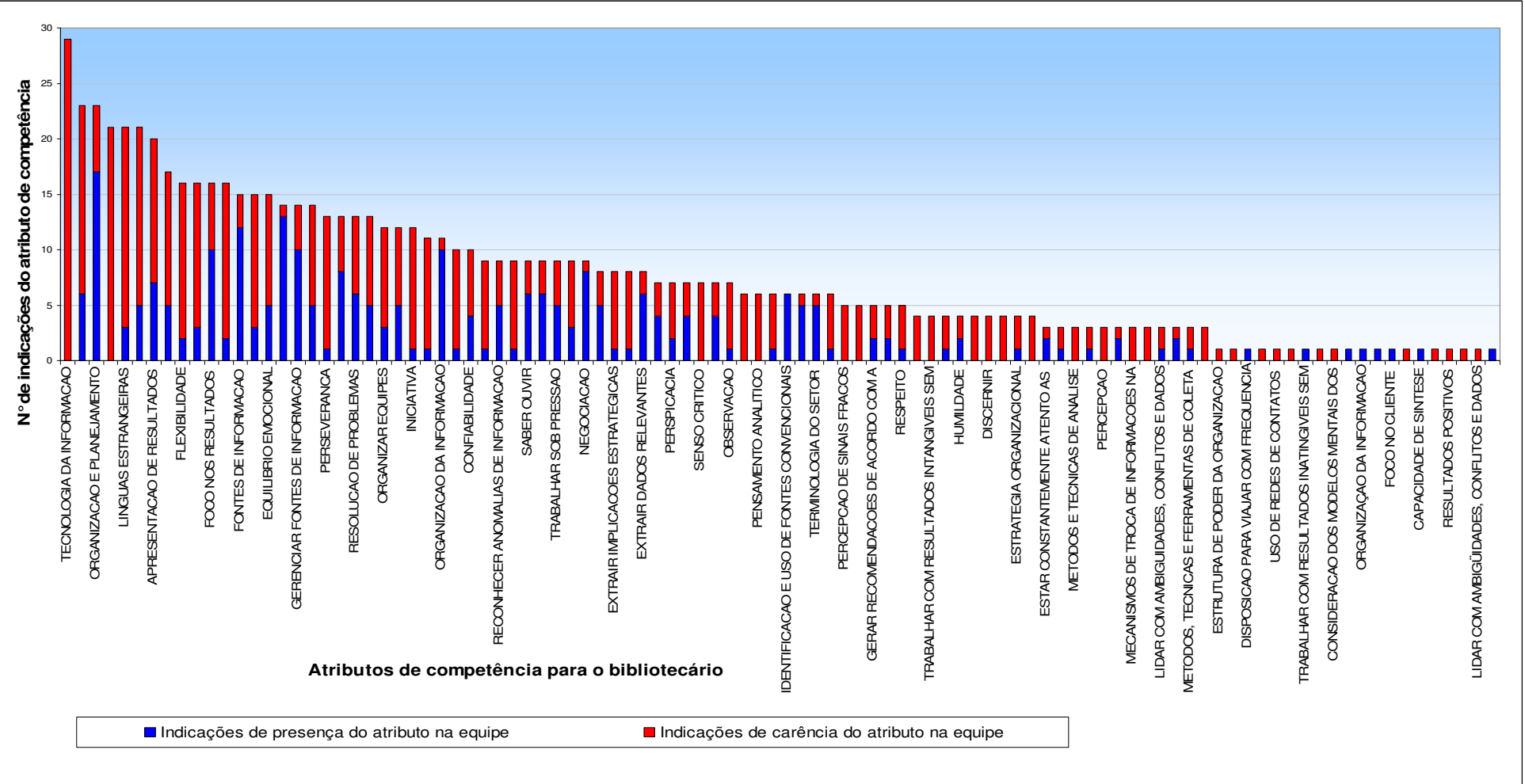


FIGURA 2 - Atributos de competência "CHA" dos bibliotecários da BCRP/USP

Fonte: Dados da pesquisa.

\section{Conclusões}

O modo como as pessoas são gerenciadas nos ambientes informativos, constitui-se em um fator determinante para o seu sucesso e para o desenvolvimento profissional daqueles que dele fazem parte. Assim sendo, o presente artigo contribui à pesquisa e ao desenvolvimento na área de Biblioteconomia e Ciência da Informação, ao propor avanços na gestão de pessoas em bibliotecas e unidades de informação, baseando-se na abordagem por competências. A pesquisa atingiu seu objetivo, que consistia em mapear os atributos de competência (conhecimentos, habilidades e atitudes) necessários à atuação do profissional da informação bibliotecário, com vistas ao estabelecimento do processo de GPPC em bibliotecas e unidades de informação.

Para a organização estudada, a pesquisa contribui como ferramenta para a gestão de pessoas, por meio da identificação das competências existentes e das que se tem por desenvolver, segundo percepções da própria equipe de bibliotecários. O mapeamento dos atributos de competências e a visualização dos Indicadores "Importância" e "Domínio da competência" ofereceram subsídios à direção da organização, para que avalie se dispõe de competências suficientes para atingir seus objetivos estratégicos e superar os desafios atuais e futuros. Também possibilitou uma reflexão sobre a atuação profissional, além de contribuir na definição de metas e direcionamento de programas de aprimoramento e desenvolvimento de competências. Outra contribuição da aplicação da sistemática foi a rápida visualização da situação da organização em relação às competências da sua equipe, no caso bibliotecários, conforme percepções da própria equipe.

Apesar da necessidade de novas pesquisas, a utilização do glossário de atributos de competência (conhecimento, habilidade e atitude) mostrou-se adequada ao mapeamento das competências do profissional da informação bibliotecário. Esta adequação pode ser verificada tanto nos atributos de competência dos profissionais da informação levantados na literatura como na realidade profissional, na qual se obteve aproximadamente $100 \%$ de cobertura na aplicação da sistemática de mapeamento, segundo a percepção dos profissionais da informação bibliotecários da BCRP/USP, portanto, constitui-se em uma importante contribuição para a área de Biblioteconomia e Ciência da Informação.

Conclui-se que a aplicação da sistemática para o mapeamento de competências em bibliotecas e unidades de informação é apropriada pelos resultados alcançados e pela sua praticidade, baixa necessidade de recursos - financeiros, de tempo, de pessoal e de conhecimentos específicos. Sua aplicação não depende de terceiros (empresas de consultoria) e também não exigi recursos externos à organização. 


\section{Referências}

AMARAL, R. M. et al. Modelo para o mapeamento de competências em equipes de inteligência competitiva. Ciência da Informação, Brasília, v. 37, n. 2, p. 7-19, maio/ago. 2008.

AMARAL, R. M.; GARCIA, L. G.; ALLIPRANDINI, D. H. Mapeamento e gestão de competências em inteligência competitiva, DataGramaZero, Rio de Janeiro, v. 9, n. 6, dez. 2008. Disponível em: <http://www.datagramazero.org.br/dez08/Art 05.htm>. Acesso em: 17 fev. 2011.

ARTHUR, M. B.; ROUSSEAU, D. M. The boundaryless career: a new employment principle for a new organization era. New York: Oxford University Press, 1996.

BRASIL. MINISTÉRIO DO TRABALHO E EMPREGO. Portal do trabalho e emprego. Classificação Brasileira de Ocupações CBO/2002. Brasília: MTE, 2007. Disponível em: $<$ http://www.mtecbo.gov.br/cbosite/pages/home.jsf $>$. Acesso em: 17 maio 2011.

COUGHLAN, P.; COUGHLAN, D. Action research for operations management. International Journal of Operations \& Production Management, Bradford, v. 22, n. 2, p. 220-240, 2002.

DURAND, T. L'alchimie de La compétence. Revue Française de Gestion, Paris, v. 127, p. 84-102, janv./févr. 2000.

DUTRA, J. S. (Org.). Gestão por competências: um modelo avançado para o gerenciamento de pessoas. São Paulo: Gente, 2001.

. Competências: conceitos e instrumentos para a gestão de pessoas na empresa moderna. São Paulo: Atlas, 2004.

FISCHER, A. L. Um resgate conceitual e histórico dos modelos de gestão de pessoas. In: LIMONGI-FRANÇA, A. C. et al. As pessoas na organização. São Paulo: Gente, 2002. pt.1, p.11-34.

FLEURY, M. T. L.; FLEURY, A. Construindo o conceito de competência. Revista de Administração Contemporânea (RAC), Curitiba, v. 5, n. espec., p. 183-196, 2001.

McLAGAN, P. Competencies: the nest generation. Training \& Development, Alexandria, v. 51, n. 5, p. 40, May 1997.

MORAES, P. O. A. Sistema de gestão da qualidade em bibliotecas universitárias. 2008. 62 f. Trabalho de Conclusão de Curso (Especialização) - MBA em Gestão de Unidades de Informação, Centro Universitário Central Paulista (UNICEP), São Carlos, 2008. 
NEVES, E. C. Profissional da informação: habilidades e competências na era do conhecimento. 2002. 125 f. Dissertação (Mestrado) - Programa de Pós-graduação em Biblioteconomia e Ciência da Informação, Pontifícia Universidade Católica, Campinas, 2002.

RUZZARIN, R. et al. Gestão por competências: indo além da teoria. Porto Alegre: SEBRAE/RS, 2002.

TARAPANOFF, K. (Org.). Inteligência organizacional e competitiva. Brasília: UNB, 2001.

VALENTIM, M. L. P. (Org.). O profissional da informação: formação, perfil e atuação profissional. São Paulo: Polis, 2000. (Coleção Palavra-Chave, 11).

. Criatividade e inovação na atuação profissional. CRB-8 Digital, São Paulo, v. 1, n. 1, p. 3-9, jul. 2008. Disponível em: <http://revista.crb8.org.br/index.php/crb8digital/article/viewFile/36/37>. Acesso em: 18 fev. 2011.

ZARIFIAN, P. Objetivo competência: por uma nova lógica. São Paulo: Atlas, 2001. 